\title{
Analysis of the Function of Value Choice on Undergraduates' Career \\ Planning
}

\section{Liubo, Chenhua}

1 School of Economics and Management, Hubei University of Science and Technology, Xianning, 437100, Hubei

2 School of Electronics and Information Engineering, Hubei University of Science and Technology, Xianning, 437100, Hubei

Key words: career planning, value choice, guidance

\begin{abstract}
This paper, through the analysis of the undergraduates' value orientation and value identity in the new age, tries to find the key of value choice and power source in undergraduates' career planning and further play the subjectivity of value choice in the implementation of undergraduates' career planning, so that to ensure the rationality of undergraduates' career planning and the accuracy of value choice.
\end{abstract}

\section{Introduction}

After taking investigation of the values of contemporary undergraduates (the generation after 90s), the educators for undergraduates, on one hand, should emphasize the development of undergraduates' subjective initiative, at the same time, they should also strengthen the mentoring and guidance work for their career planning so that to achieve the unification of social and personal value and promote the harmonious development of the individual and society. However, in career education, the guidance of value choice undoubtedly plays a fundamental role.

\section{Guidance Function of Value Choice on Undergraduates’ Career Planning}

Value is the benefit, effect and significance expressed by the interaction between subject and object and the adapting and satisfaction of object's existence and property for subject in the practical activities, besides, value generates from the relationship between human and objects and it belongs to the relation category reflecting the relationship between man and objects[1]. And value choice, in short, is the selection process that in the process of bidirectional function of subject and object, the subjects, according to their own value standard, take analysis and comparison of object's attributes and function and the potential effect of object on subject so that to obtain the biggest value on subject by using the minimum cost[2]. The value selection in this paper refers to the value choice for undergraduates in career planning and it has certain value orientation.

The so-called value orientation, essentially speaking, is the process of taking integration and dispelling of the existing various value orientation in society. The process of value orientation is not only the process of promoting certain mainstream values and promote certain values orientation according to the objective need of social development and the interests and wish of most people, but also the process of national and social inhibition, criticizing and objecting to certain values and value orientation to help people to approve the mainstream value. Value guidance clearly reflects 
the inherent requirement of value identity and identification with the core social values is the foundation for undergraduates to have good development, besides, value orientation is the social guidance of value selection for the individual or collective and it includes internally that the objects under the subject's guidance should obey and follow the guidance instructions. Speaking from the individual level, identification, as the individual rational identification for their own social view or status, is the lasting power for individual social behavior[3]. Speaking from the value pursuit and meaning care of individual life, having a definite value identification is also very necessary for people. The meaning of value identification is that it can maintain people's seeking and pursuit for spiritual home and help people establish life meaning and ultimate concern. In this multi-valued society, each individual may have the multifaceted and diversified value orientation, thus, taking value orientation form them is important and urgent. Under the mainstream discourse of value orientation, each individual will constantly develop themselves according to their own understanding of the value in the field of value life. However, the development of any individual must get the social recognition, that is only on the basis of core value identification, can they get a good and solid development foundation [4].

In this 'value explosion' age, value identification has become an important era topic. In this rapid social transformation period, only taking proper value orientation, it can guide the social members to approve and accept the socialist core value. The development of any society has a complete value pursuit and goal, and this value pursuit and goal are manifested through social value guidance. Facing the different value choices of thousands of individuals or collective, the function of social value orientation is self-evident. Contemporary undergraduates are the future of socialist cause and they are also the important subject and the main force for the inheritance of socialist core value system so taking social value guidance for this special group--undergraduates is directly related to that whether they can form the identification and reach an agreement on the socialist core value system or not, besides, it is also the important guarantee for their correct value choice in the career planning.

\section{Dynamic Effect of Value Choice on Undergraduates’ Career Planning}

People are purposeful to do anything in the society and the intensity determines the realization of objective desire purpose (i.e., success) of power factor, faith will passion rational behavior are the essential element for the success of a person [5]. Belief, and is strong spiritual motive supporting people striving, is home to people the value of our subjective initiative value selection is the foundation of the desire to achieve power. That is, the value choice is because, the desire is fruit. Because has the correct value choice, to achieve reasonable college students career planning, value choice on college students' career planning has important role in power.

For individual, the value choice is the continuous inner motive power, under which motivation, people will strive for the realization of personal value goal. For undergraduates, once the value target is set, they will struggle constantly to achieve the vocational ideal and goal in the control of personal inner spiritual power.

The power talked about here refers to the individual spirit power, which is the spiritual driving force produced by the effect of individual spirit on the main body and its behavior of individual. In the individual spirit structure, value idea and life ideal are in the leading position and they have decisive function on its moral sentiment and will quality. If the value idea, life ideal and its embedded value standard are not established on the basis of right world outlook and outlook on life, it is not possible to form correct concept of right and wrong, good and bad, not possible to assess, select and form noble moral sentiment and also not possible to form the strong will for correct ideal 
goal and noble moral sentiment[6]. At the same time, the values and life ideal also determine the nature and direction of individual spirit structure. The moral sentiment and will quality of individual subject are also the important part of individual spirit structure. One main dimension for human to explain the world is value evaluation. Each value evaluation has emotional component, which includes positive and negative subjective emotional state. Man's will is the purposeful will and it is expressed as the attention, which is not only restricted by the rational factor that whether the objective itself is correct or not, but also influenced by the correct or incorrect evaluation on the objective taken by the subject and influenced by the permeating emotional tendency. Value evaluation with intense emotional factors on the objective by the subject directly guide and regulate people's volitional activity and spiritual power produced by it.

Simply speaking, the value choice is the process of selecting object's largest value by subject. The subject of value choice in undergraduates career planning is the undergraduate and the object is society, in other words, it is the process of the selecting of undergraduates' personal maximum value choice in the society. Value choice is the direct embodiment of individual life ideal, faith, beliefs and values, and life ideal and values dominate the personal mental power, therefore, the value choice determines the force strength and endurance of mental power.

By the medium of education to let the educatees establish values meeting the requirements of social progress, which is the important education problem concerning the future of national and social development. The undergraduates are in the stage of value formation and setting, so the guiding function of education is extremely important. The teaching staff should accurately grasp the mainstream tendency for undergraduates and guide the students to form positive and healthy values through the values education. The starting point and foothold of values education is to educate students to learn to behave. The Declaration of World Higher Education in the 21st Century points out that whether one can enter the college or university or not depends on one's character rather than the superior social status[7]. The 21th Education Report submitted by the UNESCO emphasizes that, the education of the 21st century not only need to make students learn to cognize, learn to do things, but also need to learn to live together (learn to behave)[8]. Values education is to cultivate students to become the man of having both ability and political integrity, and a man with only knowledge but virtue is difficult to do things beneficial to others and society.

The good moral quality is the mental power of improving the quality of person's intelligence and it is the key factor of determining the direction of a person's ability exertion. In the social life, the richer a person's knowledge, the stronger one's ability and the bigger one's contribution to society. However, the social benefits of intelligence not only depends on one's business level, but also depends largely on his behave, that is one's thinking consciousness and professional moral level. A person without comprehensive knowledge can use morality to make up, however, a person without complete moral is difficult to use the knowledge to make up. The good of moral provides mental power and direction guidance for the true of cognition[9]. Thus: only by cultivating undergraduates of morality, we can make a really useful talents for the society. Therefore, educating the contemporary undergraduates to learn to behave should be the core of values education and it is the key for undergraduates to make the right choice.

\section{Value Choice Helps to Play Undergraduates' Subjectivity in the Implementation of Career Planning}

Undergraduates' career planning is one arrangement for the realization of undergraduates' career objectives. Whether the arrangements can be fulfilled or not needs not only the influence of value choice's guiding role and mental power, but also undergraduates' individual subjectivity in the 
implementation of career planning [10]. The representative of career development theory, Super putted forward that the career guidance should take the development of individual as the starting point and combine yourself and career into one[11] and he pointed out that the individual has the opportunity to play personal talents. It is clearly put forward the main role of personal in career and in the process of career planning, the person is the center.

The function of career planning is to let students find their orientation in the society, and then base themselves on the society, exist and develop in society. At present, the independent innovation and entrepreneurship and bi-directional career-choosing have become the mainstream of undergraduates job-application.

Choosing a career is choosing a kind of life style, and any life style should take the idea that people is a free existence as the premise and they should make efforts to achieve their freedom, namely the individual independency [12]. Marx has said that 'if the living condition that we are living allow us to choose any kind of occupation, then we can choose one that brings us the greatest dignity. However, only one kind of occupation can bring us dignity that we are not regarded as slaves when engaged in the occupation and we can take independent work in our own field.'[13] The occupation with the greatest dignity should be able to play people's free creativity, and only that kind of career can make us engaged in the work for a long-time and never feel tired, never slacken off and never get depressed.

Independent, serious and calm thinking of choosing a career is the primary responsibility for the undergraduates on a path to life. Attach important attention to the thinking that as the basis of our profession will make us in a high position in the society, improve our own dignity and make our behavior unshakable. Thus, Marx pointed out that if our living conditions allow us to choose any kind of occupation, then we can choose one that we believe in deeply. First of all, it needs to exclude the interference of external mental. Marx had talked about in Youth Employment that not only the vanity can cause sudden enthusiasm of one kind or another profession. We may also use fantasy to beautify the profession into the primacy in life. We don't have a careful analysis and do not measure all of its components, namely the weighty responsibility on us. We 'refuse to rely on the experience and the in-depth observation, but accept the deceiving of emotion and become blinded because of the fantasy [14]. Therefore, the vocational attitudes of being calm and serious, earnest and careful advocated by Marx is correct and reasonable, which also conforms to the modern scientific theory and social practice. Speaking from the sociological perspective, career choice is the key step for individual to develop from dependence to independence, from immaturity to maturity and from the social 'fringe' to social 'center', which is of great significance in the process of personal growth. When Marx wrote the Youth Employment, he was a hot-blooded youth, but the thinking about choosing a career shows the infrequent calm, seriousness and mature of his age.

\section{Conclusion}

In colleges and universities, the ideological and political education workers are also advocating the undergraduates to learn to study, learn to live, learn to think, and learn to cooperate with others, which is in the same way with the value choice of career planning. For undergraduates, owning a healthy physical condition is not only the judgment to career choice, also the objective guarantee for the effective embodying of value choice in the implementation of career planning. 


\section{Acknowledgements}

2010 Guiding Project(2010b233) , Humanities and Social Science Research Project, Education Department of Hubei province

\section{Bibliography}

[1] Zhang Yaocan etc. Modern Ideological and Political Education[M].Beijing:People's Publishing House,2006: 216.

[2] Karl Marx and Frederick Engels(Volume 19)[M].Beijing:People's Publishing House(Edition in 1963):406-409.

[3] Pan Zhengyun, Peng Shuisheng, Discussion of Value Choice[M].Journal of Zhejiang University 8(4), 1994 (12) : 117-122.

[4] Chen Zhanglong, Zhouli, Study of Values[M].Nanjing.Nanjing Normal University Press,2004: 227.

[5] Wang Xinyan.Value Identification and Values Conflict in the Globalization[J].Philosophy Research,2002(11).

[6] Yuan Guiren, Values Introduction[M].Beijing:Beijing Normal University Press,1991: 530.

[7] Luo Yuting.Levels and Structure of Mental Power[J].Ideological and Theoretical Education Tribune,2003(12).

[8] Karl Marx and Frederick Engels(Volume 40)[M].People's Publishing House,1995: 339.

[9] Cheng Liangyue, Wang Jiannong.Career Guidance[M].Career Mentor.2007（5-6） : 50.

[10] Karl Marx and Frederick Engels V.40[M].Beijing:People's Publishing House,1982: 3.

[11] Burkhardt.Culture of Italian Renaissance[M].Beijing:Commercial Press, Edition of 1979:350.

[12] Yang Jinzhou.Contemporary Understanding of Marks' Work Thinking of Career Choice for Youth[J].School Party Construction and Ideological Education, 2008:65

[13] Karl Marx and Frederick Engels(Volume 40)[M].Beijing:People's Publishing House,1982 : 6.

[14] Karl Marx and Frederick Engels(Volume 40)[M].Beijing:People's Publishing House,1982: 3-7. 